\title{
La fe en los escritos de Pablo
}

Eduardo de la Serna

\section{Resumen}

El término fe/creer dice algo según quién lo dice y quién lo lee. El modo en el que Pablo lo utiliza puede verse con más precisión al ver en qué contexto lo utiliza, o algunas características, como ver que la fe se entiende como fruto, como don, como algo colectivo, histórico, como "fe de Cristo", que es misionera y está ligada a la predicación, a la misión del apóstol, como adhesión a una persona: Cristo; $y$ además, con matices propios en cada comunidad/carta.

Palabras-clave: Fe - crer; Cristo; predicación; misión.

\begin{abstract}
The term faith/belive says something different according to whom is said it and the one who reads it. The mode in which Paul uses it can turn more precisely on having seen in what context it uses it, or some characteristics as, on having seen that he understands it as fruit, as gift, as something collective, historical, as "Christ's faith", it's missionary and tied to the preaching, to the mission of the apostle, and as adhesion to a person: Christ; and in addition,
\end{abstract}


with own shades in every community / letter.

Abstract: Faith - to believe; Christ; preaching; mission.

\section{Introdução}

Encontrándonos en lo que se ha llamado el "Año de la fe" es importante, y quizás indispensable, ver qué dicen los autores del Nuevo Testamento sobre este tema tan fundamental. Y dentro del Nuevo Testamento, los escritos de Pablo son particularmente importantes ya que pareciera ser un autor determinante en la comprensión de este tema, y también en posteriores conflictos intra eclesiales, muchos -aunque tardía- afortunadamente superados. ${ }^{1}$

Sin duda, uno de los elementos principales para comprender este tema tan fundamental en el pensamiento paulino, y cristiano, radica en entender que quiere decir "fe" en la mente del Apóstol. Una mala comprensión de este punto de partida, llevará a conclusiones erradas; y en muchos casos, como los aludidos más arriba, a decisiones que con el tiempo hemos de lamentar. Un ejemplo que parece pertinente mostrar (y no es ajeno a la tensión católica - luterana) podemos encontrarlo en la carta llamada de "Santiago". Allí, en aparente conflicto con Pablo, el autor sostiene que las obras hacen visible la fe, y pronuncia una frase contundente: “ ¿Tú crees que Dios es uno? ¡Haces bien! También los demonios creen. ¡Y tiemblan!” (2,19; “die Teufel glauben’s auch und zittern" traduce Lutero en 1545). Para entender a Pablo, y para tener claro en qué sentido debemos entender la raíz "fe/creer" en los escritos paulinos, parece razonable señalar que Pablo ¡jamás! podría haber dicho que "los demonios creen". Parece haber dos modos diferentes de entender la "fe" en ambos escritos. Dos modos contrapuestos.

Para introducirnos en el tema, parece importante ver, aunque brevemente, qué se entiende por fe/creer en el medio ambiente paulino. Qué dice Pablo cuando dice fe; qué entienden sus destinatarios cuando oyen fe. Pablo es judío, y judío helenista. Es conocedor de las escrituras. Sus destinatarios, en cambio, en su mayoría no son de origen judío. La gran mayoría de ellos provienen

\footnotetext{
${ }^{1}$ Me refiero especialmente a la declaración conjunta Católica - Luterana sobre "la Justificación" de 1999. Siempre queda la "sensación" o sospecha, si la poca dedicación particular a los estudios sobre Pablo en la Iglesia Católica romana no tienen cierto origen en la crisis protestante, o el supuesto conflicto "Pedro - Cefas" narrado en Gal 2,11-14. Quizás también haya que remontarnos a estos momentos para explicar el poco suceso del así llamado "Año paulino".
} 
del paganismo y se han incorporado a las comunidades cristianas sin "pasar previsamente por el judaísmo oficial" (= sin circuncisión).

Siempre es difícil saber o precisar qué tan judíos y qué tanta novedad pretenden tener y vivir, y predicar los primeros seguidores de Jesús, Pablo incluído. Es evidente que el tema no es uniforme, y que mientras algunos acentúan "lo judío" y minimizan la novedad, otros, por el contrario acentúan tanto "lo nuevo" que parecen casi negar lo "judío". Textos joánicos como "la Pascua/Fiesta de los judíos" $(2,13 ; 5,1 ; 6,4)$ o el discurso puesto en boca de Esteban por el autor de Hechos (7,48: "Dios no habita" en el Templo), o la "carta" a los Hebreos parecen prácticamente dar por terminada la etapa de "preparación", o lo "antiguo" judío, tanta es la novedad. Otros textos o personajes, en cambio, parecen reducir casi al mínimo la novedad (como, por lo que parece, es el caso de "los de Santiago"; cf. Gal 2,12), y quizás también la carta de "Santiago" o el Evangelio de Mateo... Pero, ¿y Pablo?

No podemos dejar de señalar algo que es cada vez más evidente: Pablo no sólo es de "origen" judío, sino que Pablo vivió sabiéndose judío, predicó sabiéndose judío y hasta el último momento del que tenemos noticias, se sintió judío. Hablar de un Pablo "cristiano", por verdadero no deja de ser "anacrónico". Pero no sólo esto; además, Pablo cree y está convencido que sus comunidades son "verdaderamente judías". No de un "nuevo Israel” (algo más propio de Mateo), ni siquiera de un "verdadero Israel" (como si el otro Israel fuera "falso"). Pablo sabe que con la Pascua han llegado los nuevos tiempos, el tiempo escatológico; se ha derramado el espíritu, y -como algunos profetas lo habían señalado- al llegar estos tiempos los paganos reconocerán al Dios de Israel, se incorporarán a Israel:

Reúnanse, vengan, acérquense juntos, supervivientes de las naciones: No discurren los que llevan su ídolo de madera y rezan a un dios que no puede salvar. Declaren, expongan las pruebas, que deliberen juntos: ¿quién anunció esto desde antiguo, quién lo predijo desde entonces? ¿No fui yo, el Señor? No hay otro Dios fuera de mí. Yo soy un Dios justo y salvador, y no hay ninguno más. Vengan a mí para ser salvados, confines de la tierra, porque yo soy Dios, y no hay otro. Lo juro por mi nombre, de mi boca sale

\footnotetext{
${ }^{2}$ Por ejemplo, MARTIN, D. B., New Testament History and Literature, New Haven-London: Yale University Press 2012, p. 102 supone que Mateo pretende que los gentiles, al convertirse, deben ser circuncidados; algo semejante afirma D. C. Sim (siguiendo a S.G.F. Brandon, 1951) al sostener que el evangelio de Mateo es "antipaulino": SIM, D.C., "Matthew's Antipaulinism: A neglected feature of Matthean Studies", HTS 58/2 (2002) p. 767-783.
} 
una sentencia, una palabra irrevocable: Ante mí se doblará toda rodilla, por mí jurará toda lengua. Dirán: Sólo el Señor tiene la justicia y el poder. A él vendrán derrotados los que se enfurecían contra él, por el Señor triunfará y se gloriará la estirpe de Israel (Is 45,20-25).

Sólo que esta incorporación no ocurre por la circuncisión "en la carne", que nos "vuelve judíos" sino por una circuncisión del corazón (Jer 4,4; Dt 10,16; 30,6; cf. Rom 2,29; Fil 3,3), el bautismo. Incorporados a Cristo, "en Cristo", los paganos son injertados al pueblo de Dios para dar frutos (Rom 11,16-24). En coherencia con los profetas, Pablo sabe que muchas veces Israel no aceptó o no reconoció a Dios (en Rom 9-11 desarrolla extensamente el tema que lo angustia; notar la cita de Oseas 2,25: ya "no mi pueblo" releída en Rom 9,25); pero sabe también que hay un resto que permanece (Is 1,$9 ; 10,20-22 ; 11,11.16 ; 28,5 ; 37,31.32 ; 46,3 \ldots$ textos también releídos en Rom 9,27-29; 11,5), y a ese resto se incorporan aquellos de origen pagano (injertados, Rm 11,17.19.23.24) y también pueden ser “injertados" de nuevo aquellos desgajados en un momento por no aceptar la novedad que viene con Cristo (v.23); este injerto ocurre "en Cristo" donde se integran los nuevos miembros. Se incorporan, precisamente, por la fe.

Otro elemento a tener en cuenta es que las cartas paulinas no son "kerigmáticas", entendiendo esto como "primer anuncio". Son cartas catequéticas, a comunidades que ya han recibido el anuncio y han "creído" en él. Este "primer anuncio" tiene como objetivo claro "la fe", y las cartas pretenden que esa fe aumente. Es decir, son dirigidas a creyentes, y con el objetivo de profundizar la fe, aclarar aspectos confusos, dudas, problemas que la fe suscita en las comunidades y por los cuales Pablo es consultado, o se cree en la necesidad de intervenir.

En este ambiente de novedad-continuidad, emisor-destinatarios, es que debemos entender el sentido en el que Pablo resalta la centralidad de la fe para la vida de los seguidores de Jesús.

\section{La fe en el contexto y médio ambiente paulino}

\section{La fe para el ambiente judio}

- En el judaísmo palestinense, usualmente la raíz אמן ('mn) refiere a "creer en", "tener confianza en", con la idea fundamental de "tener firmeza". La imagen puede ser bien la del árbol que asienta sus raíces, o la de la casa edificada sobre tierra firme. La importancia dada a la idea de Dios como "Roca" (Dt 32,4-37; 
1 Sam 2,2; 2 Sam 22,2.32.47; Sal 18,3,32.47; 19,15...) sin duda debe ubicarse en este sentido; $\mathrm{y}$-del mismo modo- debe entenderse la crítica profética a quienes buscan "seguridad" o "confianza" en lo que no es Dios (sea porque no lo es atentar contra el primer mandamiento- o por una manipulación del verdadero Dios -contra el segundo mandamiento-) lo cual es presentado como idolatría. Sólo en Dios tiene sentido estar firme, edificar la vida, "Él es la Roca, su obra es consumada, pues todos sus caminos son justicia. Es Dios de la lealtad, no de perfidia, es justo y recto" (Dt 32,4).

- En el judaísmo helenista el término tiene algunos matices interesantes: en el Sirácida, la imagen es la de "confiar" (Sir 2,6.8.10; 4,16; 11,21; 12,10; 19,15; $32,24)$ o de "fidelidad" $(1,14.27 ; 6,14-16 ; 15,15 ; 32,23)$ o incluso "seguridad" $(31,23)$ o "credibilidad" $(37,22.23 ; 48,22)$. En Sabiduría se alude a los que están

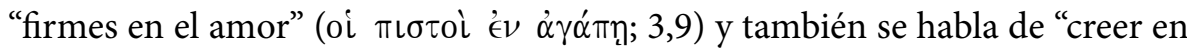
el Señor" $(12,2 ; 16,26)$. "Las obras de Dios son verdaderas y todos sus caminos son juicio fiel"; hay que confiar sólo en Dios (Odas 2,4.20). En ocasiones, la fe se asemeja a la esperanza: "los que creen que para Dios no están muertos" como no lo están Abraham, Isaac o Jacob $(4 \mathrm{Mac} 7,19)$, esos caminan en la

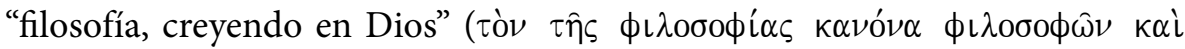

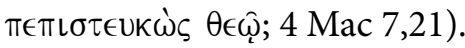

Desde una perspectiva ciertamente "filosófica", Filón de Alejandría afirma: “¿Cómo puede uno creer en Dios?: Viendo que todas las cosas cambian

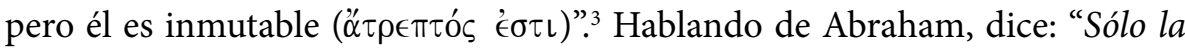

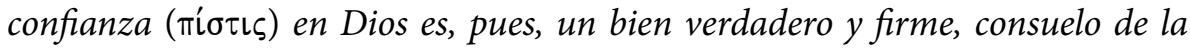
vida, plenitud de las buenas esperanzas, escasez de lo malo, impulso por lo bueno, desconocimiento del infortunio, conocimiento de la piedad, completa fortuna, vida firmemente apoyada y puesta en la causa de todas las cosas y que todo lo puede, y quiere sólo lo excelente"4 (Abraham 268).

\section{La fe para el ambiente greco-romano}

- En el helenismo, el término parece señalar alguna diferencia: está asociado con los oráculos; por ejemplo, se dice de Sócrates: “¿Qué otra cosa se podía hacer sino recurrir a los dioses? Él creyó ( $\pi\llcorner\tau \tau \in v ́ \omega \nu)$ en los dioses. ¿Cómo podría creer que los dioses no existen (como afirman sus opositores)?”

\footnotetext{
${ }^{3}$ FILÓN DE ALEJANDRÍA, Interpretación alegórica (Alleg. Interp. 2.89), Obras Completas, Buenos Aires: Acervo cultural 1975, t.I p.106.

${ }^{4}$ FILÓN DE ALEJANDRÍA, de Abraham, Obras Completas t.III p. 253.
} 


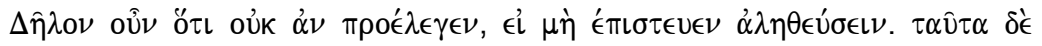

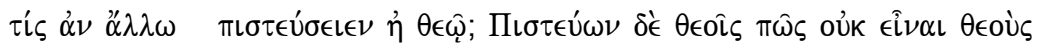

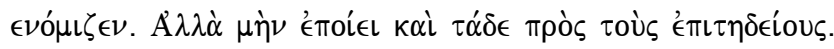

Plutarco afirma que la fe es evidente, "los dioses son los garantes de que todas las cosas existan". Por eso el ateísmo es criticado tanto como la superstición como un "inadecuado conocimiento de los dioses", "la verdadera religión se encuentra entre ambas". Así empieza Plutarco en "sobre la superstición ( $\pi \epsilon \rho \grave{~}$ $\delta \epsilon \iota \sigma\left\llcorner\delta \alpha \iota \mu \nu \nu^{\prime} \alpha \varsigma\right)$ :

"La ignorancia y el desconocimiento sobre los dioses corren ya desde su origen por dos canales, de los cuales, el uno produce, en los caracteres obstinados, como en suelos duros, el ateísmo, y el otro, en los caracteres blandos, como en suelos húmedos, la superstición". ${ }^{8}$

- En cambio, en el Imperio romano el término adquiere otras connotaciones particulares.

En general se mantiene un contexto semejante al helénico; Marco Aurelio habla de quienes "creen en los dioses" (Meditaciones 3). ${ }^{9}$ Pero en el mundo romano, la "fides" es una virtud pública, incluso divinizada, como tantas otras virtudes que reciben culto público. Lo religioso, no pertenece a la esfera "privada" sino que es lo que da sentido al mundo tal cual es (y tal cual Roma desea que sea) y no se separa lo social, lo cultural y lo político. El templo a la diosa "Fides", en la región sud-oeste del area Capitolina lo demuestra. La nota de "fidelidad" es la preponderante, y supone fidelidad a Roma. Cicerón, por ejemplo, contrasta la actitud de los galos (que practican sacrificios humanos) con la "fides romana", o también que "Galba, renunciando al derecho de propia defensa e implorando la fe del pueblo romano, lo presentó llorando...”

${ }^{5}$ JENOFONTE, Memorabilia et alia, Massachusetts - London: Harvard University Press 1997, p.5. ${ }^{6}$ PLUTARCO, Obras morales y de costumbres, Madrid: Sobre la superstición (Mor. 164 E) ed. Gredos 1986 t.II p. 289 (ver también Mor 359-360; 757D).

${ }^{7}$ PLUTARCO, ib 171E p. 320.

${ }^{8}$ PLUTARCO ib. 164E p. 289.

${ }^{9}$ MARCUS AURELIUS ANTONINUS. His Meditations concerning himself , (Medit III 16), London - New York: Loebs Library 1916, p.63. 
(Galba pro sese et populi Romani fidem implorans). ${ }^{10}$

"Los intentos de asociar las cualidades con grupos particulares también fueron hechos, y desafiados, por motivos prácticos. Agathocles intentó acentuar las relaciones positivas entre 'Roma' y fides atribuyendo la fundación del primer templo de fides sobre el Palatino a Rhome aún antes de que la ciudad fuera fundada, mientras Plinio el Viejo usó más tarde una etiología del templo de pietas para privilegiar la asociación 'de los Romanos' y aquella cualidad". ${ }^{11}$

Ciertamente no se entiende del mismo modo esta "fides/fidelidad" en tiempos de la República que en tiempos del Imperio. La concentración en el Emperador lleva a reconocer que dicha "fidelidad" es concretamente a su persona. Los trabajos sociológicos que analizan la relación "patrón-cliente" dan un paso más en este tema. Veamos:

"El término romano central e intraducible auctoritas va tanto desde los aspectos materiales y políticos hasta el intelectual y finalmente la autoridad moral. La auctoritas del patrón incluye un sentido activo en relación al bienestar de sus clientes. Está estrechamente relacionado con otros términos romanos como fides (= pistis en griego; "confiar", "fe"). Así, el hombre de estado es un "garante de la confianza que debe estar operativa en todos los niveles de la res publica". Es esencial, por supuesto, para la auctoritas del patrón o del hombre de estado ser opulento. Y, en ese sentido, Augusto era el más opulento y el máximo benefactor en la historia romana aunque la mayor parte de sus riquezas fueran, por supuesto, ganadas durante las guerras civiles". ${ }^{12}$

\section{Y también:}

"En un lenguaje que para muchos resulta familiar de las cartas de Pablo, o también de los escritores latinos y griegos e inscripciones, una cuestión central de la ideología del imperialismo romano, deriva de las relaciones

${ }^{10}$ CICERON, Bruto: de los oradores ilustres, México: Universidad Nacional Autónoma de México 2004, p. CX.

${ }^{11}$ CLARK, Anna J. Divine Qualities. Cult and Community in Republican Rome, Oxford: Oxford University Press, 2007, p.259; en p.48 un mapa de los diversos templos con las virtudes divinizadas, "fides" entre ellas.

12 "Introduction", en R. Horsley, (ed.), Paul and Empire. Religion and Power in Roman Imperial Society, Pennsylvania: Trinity Press International 1997, p.15. 
patrón-cliente, resulta que los romanos mostraban su fides $=$ pistis, protección, ayudando a sus "amigos", mientras que los amigos de Roma eran celebrados por su fides $=$ pistis, esto es, su lealtad a Roma" ${ }^{13}$

La fuerte carga política del término "fides/pistis" en el ambiente greco romano en el que Pablo desarrolla su ministerio, no es ajena, tampoco a la carga política que tienen otros términos tales como: hijo de Dios, evangelio, ekklesía, járis/gratia, pax... ${ }^{14}$ Esto nos invita a notar un franco objetivo contra-cultural del lenguaje de Pablo, y una fuerte intención subversiva y antiimperialista. ${ }^{15}$

Teniendo esto en cuenta, creemos importante notar que para Pablo, la fe es ante todo un don (II), un don al que se accede por mediaciones y en la historia. Este don de la fe, tiene un contenido, aquello/aquel en lo que/quien se cree (III) o más precisamente, es una adhesión a una persona, Jesucristo (IV). Señalado esto, y teniendo en cuenta que Pablo no es un teólogo sistemático sino que despliega una "teología en epístola", ${ }^{16}$ concluiremos señalando brevemente el uso de la raíz $\pi\llcorner\sigma \tau--$ en las diferentes cartas paulinas notando algunos aspectos centrales de la fe con sus características propias $(\mathrm{V})$.

\section{La fe como don}

\section{Don del espiritu}

Para comenzar a entender la fe en Pablo es bueno notar que para él se trata de un don de Dios. Siempre es un tema interesante, aunque no sea este el lugar de responder, si de don se trata, a quién, por qué, para qué, y por qué a unos parecería que no les es dado el don, siendo este tan importante. Señalemos dos textos a modo de ejemplo.

La unidad Fil 1,27-30 resulta importante, y merece algunas notas

${ }^{13}$ GARNSEY, Peter and SALLER, Richard, "Patronal Power Relations". En: R. Horsley, (ed.), Paul and Empire. Religion and Power in Roman Imperial Society, Pennsylvania; Trinity Press International 1997, p. 93.

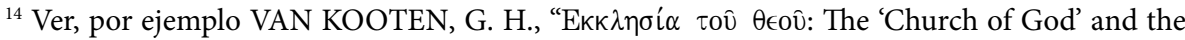

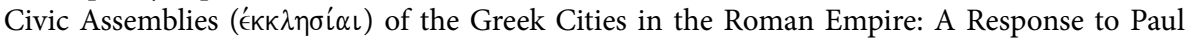
Trebilco and Richard A. Horsley", NTS 58 (2012) p. 522-548 donde -a diferencia de Trebilcoplantea que las asambleas ciudadanas son decisivas en el uso de ekklesía, pero -a diferencia de Horsley- sostiene que no se trata de anti-imperialismo sino de otra ciudadanía...

${ }^{15}$ Puede verse, por ejemplo de ÁLVAREZ, D., Pablo y el Imperio Romano, Salamanca: Sígueme 2009.

${ }^{16}$ BARBAGLIO, G., La Teología de San Pablo, Salamanca: Secretariado Trinitario 2005, p. 9-10. 
aclaratorias. Para empezar, señalamos algunas curiosidades. La idea de ciudadanía, sólo se encuentra en las cartas paulinas en el Nuevo Testamento y exclusivamente en Filipenses, y es también en Filipos -según Hechos- donde por primera vez (y única antes del juicio en Cesarea) en que Pablo alude a su ciudadanía romana (16,37, aunque la palabra "ciudadanía" no aparece en el texto griego). Es también Filipenses la única carta donde Pablo alude a (un) pretorio $(1,13)$ y a la "casa del César" $(4,22)$, lo que ha hecho pensar a algunos en un cautiverio romano. El lugar de la prisión paulina al escribir Filipenses sigue en debate, y tres propuestas son las vigentes: una prisión en Efeso, en Cesarea o en Roma. ${ }^{17} \mathrm{El}$ contexto anti-imperial que se ve claramente en Filipenses, de todos modos, puede inferirse sin necesidad de recurrir a una hipotética prisión romana.

Las traducciones del texto no hacen -habitualmente- justicia a muchas

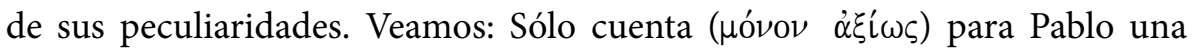
ciudadanía (

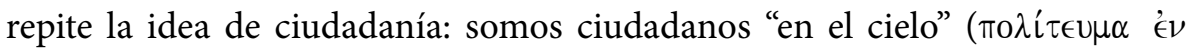
oủp $\alpha \nu$ ois). Para una comprensión integral del término es importante recordar que Filipos era una Colonia Romana, los miembros de la elite de la ciudad, por tanto, eran ciudadanos romanos. Y esto implica "fides" al Emperador, y también reconocimiento a su patronazgo, reconocerlo como Dios y Señor. El poder del Emperador, que se hace sentir en todo el Imperio, es celebrado en las colonias, es exaltado y honrado en majestad, poder y auctoritas. Los cristianos, en cambio, reconocen como "señor" a Jesús, que es "exaltado" por Dios al humillarse, vaciarse y tomar forma de esclavo. Es esto lo que Pablo invita a "sentir en Cristo" (2,5-11). El señor de Pablo no está en Roma, sino en los cielos, e invita a vivir -en Filipos- según el Evangelio. ${ }^{18}$ Esta "ciudadanía

\footnotetext{
${ }^{17}$ Todas estas prisiones paulinas son hipotéticas. La prisión en Efeso parece desprenderse de textos paulinos (1 Cor 15,32; 2 Cor 1,8; cf. 1 Cor 16,8-9; Rom 16,3-4); las prisiones en Cesarea y Roma se desprenden de Hechos $(23,23-26,32 ; 28,16-31)$ pero muchos dudan de la veracidad histórica de Hechos, redactado evidentemente en paralelo con la Pasión de Jesús en Lucas destacándose, así, una clara intencionalidad teológica: Pasión de Cristo - Pasión de Pablo; esto lo hemos señalado en DE LA SERNA, E., "La figura de Pedro en los escritos de Pablo", RevistB 70/3-4 (2008) p. 133-171, 136.

${ }^{18}$ Es muy importante señalar la diferencia notable entre este texto de Pablo y uno semejante de Filón de Alejandría: “Tal es el motivo por el que todos los considerados sabios por Moisés son presentados residiendo transitoriamente en un determinado lugar. Es que sus almas, si bien, movidas por el deseo de ver y aprender, tienen la costumbre de realizar viajes a la naturaleza terrestre, jamás emigran definitivamente del cielo a otra morada. De ese modo, una vez que, situadas temporariamente en cuerpos, han contemplado todos los objetos mortales de los sentidos externo, se elevan nuevamente
} 
del evangelio" es, para Pablo, "fe del Evangelio" ( por ella deben "competir conjuntamente en un sólo espíritu y una sola alma"

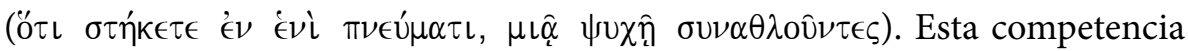
es con adversarios que desconocemos, pero lo cierto es que a "ustedes" (los filipenses) "se les ha concedido" (pasivo divino aoristo, que indica que en

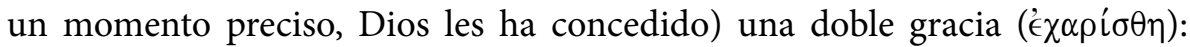
la fe y el padecimiento por Cristo. Este padecimiento "en ese combate ( $\alpha \gamma \hat{\omega}$ $\nu \alpha$ ) como en el que me vieron y ahora oyen de mí". Esto nos invita a suponer que los adversarios son los mismos que han encarcelado a Pablo, y quienes hacen padecer a los filipenses. Lo cierto es que padecer por Cristo asemeja a los miembros de la comunidad con el apóstol, y Pablo señala que en "nosotros abundan los sufrimientos de Cristo" (2 Cor 1,5).

En este contexto es que Pablo destaca que el otro don de la gracia es la fe, fe que permite a los filipenses "luchar / competir" ${ }^{19}$ para que sea realidad la "ciudadanía del Evangelio".

En cuanto don, la fe es dada por el espíritu. En la lista de dones de la gracia $(\chi \alpha ́ \rho\llcorner\sigma \mu \alpha)$-entre otros- alude a la "fe" (1 Cor 12,9), cosa que repite en una nueva lista más breve en 1 Cor 13,2. Es posible que Pablo en estos casos aluda a un tipo de "fe" particular ("fe capaz de mover montañas", por tanto quizás ligada a milagros) ya que en seguida retomará el tema con un sentido aparentemente diferente al destacar que "el amor todo lo cree" y que "ahora permanecen la fe, la esperanza y el amor" (13,7.13).

En un nuevo catálogo, en Ga 5,22, repite que la fe es "fruto del espíritu". El texto está presentado en contraposición con "las obras de la carne". En este caso surge la pregunta por qué no habla de "obras" del espíritu sino de "fruto", y por qué en singular (no dice "frutos"). Siendo que en toda la carta Pablo señala

hacia el lugar del que primeramente habían salido, considerando la patria de los cielos en la cual ellos

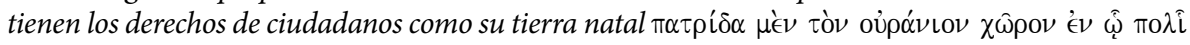
$\tau \in \dot{0} \nu \tau \alpha \iota) ; y$ que la terrestre, donde residieron de paso, es tierra extranjera. Si para aquellos que han fundado una colonia la región que los ha recibido se convierte en la patria en vez de la metrópoli, para los que simplemente se hallan viajando por tierra extranjera la patria sigue siendo aquella que los vio partir y hacia la que anhelan retornar". FILÓN DE ALEJANDRÍA, de la Confusión de Lenguas (de Conf. Ling. 77-78), Obras Completas t.II p.186. Sin dudas, este tipo de lectura (como también ocurre con la hecha -por ejemplo- al término "extranjeros" en 1 Pe 2,11 justamente criticada por J. Elliott en ELLIOT, J., Un hogar para los que no tienen patria ni hogar: estudio crítico social de la Carta primera de Pedro y de su situación y estrategia, Navarra: Verbo Divino, 1995) refleja una mentalidad platónica de la que indudablemente Pablo está muy lejos, como estamos señalando.

${ }^{19} \mathrm{El}$ verbo $\sigma \nu \nu \alpha \theta \lambda \lambda^{\prime} \omega$ puede tener referencias a las competencias deportivas (atletas), pero parece una metáfora militar. Sólo se encuentra en Fil en todo el NT, y la otra ocasión la encontramos en 4,3. 
el contraste entre la fe y "las obras de la ley", es posible que haya buscado evitar una connotación positiva del término "obras". Por otro lado, el uso del singular ha hecho a muchos pensar que Pablo está pensando en el amor como "el único fruto", mientras que los restantes ocho términos son especificaciones del mismo. También se ha pensado en que los términos se agrupan en tres ternas: la primera como circunstancias del amor, la segunda como disposiciones del amor y la tercera como caracteres que acompañan al amor. ${ }^{20} \mathrm{La}$ fe se encuentra en el tercer grupo junto con la dulzura / mansedumbre / modestia (

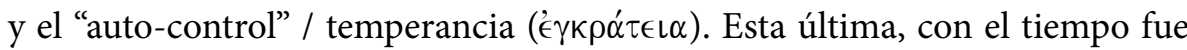
motivo de rigorismo (los encratitas), especialmente en temas sexuales, pero no parece ese el sentido en esta parte. Si debe leerse -como parece- en paralelo antitético con los "vicios" de 5,19-21, los dos últimos aluden a desbordes en comidas y bebidas (borracheras y orgías, idea que se repite en Rom 13,13) y quizás en este sentido alimenticio deba entenderse el (auto)control o dominio. La fe, unida a la mansedumbre las encontramos en Sir 1,27, donde afirma que Dios se complace en ellas; y 45,4 donde señala que Dios separó a Moisés para sí en "mansedumbre y fe"; esto parece indicio de que en ocasiones se las presentaba juntamente en el ambiente judeo helenista. De todos modos, al destacar la característica de fruto, el acento está puesto en que no se trata de una "obra", de algo que el creyende debe vivir / practicar, sino de algo que por poseer el espíritu "fluye", "se da”. A esto llama Pablo "vivir según el espíritu" (Ga 5,16.35) lo que supone "andar según el espíritu”. En este caso, la fe tampoco parece referir a aquella instancia superior que moviliza toda la carta sino a un modo de carácter movido por la presencia del espíritu.

\section{Meditación del apóstol}

En cuanto apóstol, toda la vida de Pablo está en función de "evangelizar", él lo dice claramente: "Ay de mí si no evangelizo..." (1 Cor 9,16) Es para esto que Pablo es, es el sentido de su apostolado: anunciar la buena noticia. Pero la predicación tiene como objetivo conseguir la fe en los destinatarios, es instrumento para la fe. La fe es, en este caso recepción y respuesta.

- fe y palavra

${ }^{20}$ DE BOER, M. C., Galatians. A Commentary, Louisville-Kentucky: Westminster J. Knox Press, 2011, p. 363-366. 
En 1 Cor 1,21 Pablo vuelve a tomar la idea de lo que a Diosle complace: "por

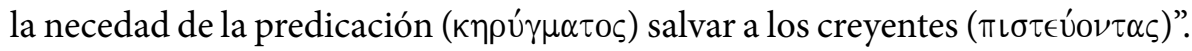
Como se ha dicho, el kêrigma busca la fe, y esta fe alcanza la salvación. ${ }^{21}$ En toda la unidad Pablo se concentra en la predicación, Pablo es enviado / apóstol ( $\left.\dot{\alpha} \pi \epsilon^{\prime} \sigma \tau \epsilon \iota \lambda \lambda^{\prime} \nu\right)$ para evangelizar $(\epsilon \dot{U} \alpha \gamma \gamma \epsilon \lambda \hat{\imath} \zeta \in \sigma \theta \alpha \iota)$. Esta predicación es "palabra de la cruz" y la cruz es necedad y escándalo. Pero en la unidad -y no sólo aquí- es evidente que para Pablo hay una estrecha interrelación entre el contenido de la predicación y la vida del predicador. Esa cruz que predica, se refleja en la misma comunidad ("no hay muchos sabios según la carne, ni muchos poderosos, ni muchos bien nacidos $(\epsilon \dot{\gamma} \gamma \in \nu \in \hat{\imath} \varsigma)$... ha escogido lo necio...

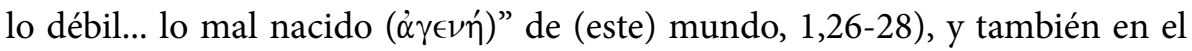
mismo predicador "no fui con el prestigio de la palabra o de la sabiduiría... no quise saber sino a Jesucristo crucificado... pues en debilidad, en temor y mucho temblor fui a ustedes" $(2,1-3)$. La predicación es necia $(1,21)$ como es necia la palabra de la cruz $(1,18)$ y la cruz misma $(1,23)$, y las cosas del espíritu de Dios lo son $(2,14)$ porque Dios mira con otros ojos $(3,19)$ : las cosas del espíritu son

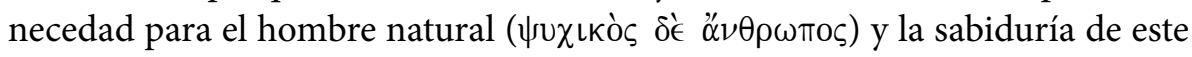
mundo es necedad para Dios. Es interesante el contraste expreso que Pablo presenta entre la cruz y una serie de categorías que son tenidas por valiosas en su ambiente (y seguramente también por los corintios): palabras de sabiduría y persuasión. El acceso a la fe no debe originarse en la fascinación por discursos retóricos sabios, sino por la asimilación a la necedad y el escándalo de la cruz.

Destaquemos brevemente dos aspectos que parecen estar en el trasfondo de esta unidad. En primer lugar, como buen judío, Pablo es sumamente sensible a la idolatría, tema particularmente importante en la Primera Carta a los Corintios. ${ }^{22}$ Como ya se ha dicho, por idolatría no ha de entenderse solamente la violación del primer mandamiento adorando divinidades extranjeras, sino también poner la confianza y la búsqueda de seguridad en aquello que no es Dios (aunque sean cosas muy cercanas a Dios, como el templo, la alianza, el Día de Yahvé). ${ }^{23}$ Poner la confianza y afirmarse en algo que no sea solo Dios, se

${ }^{21}$ DE LA SERNA, E., "El kerigma de Pablo. Una mirada al ministerio paulino", Theologica Xaveriana 61 (No 172) (2011/2) p. 509-536.

${ }^{22}$ Sobre esto hemos trabajado en: DE LA SERNA, E., "La Idolatría en 1 Corintios, ¿Una Clave de Interpretación?” En V. M. Fernández y C. M. Galli (eds.), “Testigos... y Servidores de la Palabra” Lc 1,2. Homenaje a Luis Heriberto Rivas, Buenos Aires: San Benito, 2008, 111-134.

${ }^{23}$ Cf. SICRE, J. L., Introducción al profetismo bíblico, Navarra: Verbo Divino 2011, p. 377-394. 
aproxima a la idolatría. En este caso, Pablo parece estar alerta ante los que ponen su confianza en la excelencia de la predicación de algunos (¿los del grupo de Apolo?). En este caso, esta excelencia puede disimular la importancia que debe tener la debilidad de la cruz; de allí la insistencia en la identificación entre el contenido de la predicación -la cruz-, el modo de la predicación, "débil" (como la cruz, 1,25), y la debilidad del apóstol $(2,3 ; 4,10)$. Poner la confianza en "una buena predicación" puede ponernos en el terreno de la idolatría.

Otro tema que no es ajeno a este es que Pablo suele utilizar tres verbos para expresar realidades semejantes. "Gloriarse" ( $\delta$ o $\xi \alpha \zeta \omega)$ que podemos decir

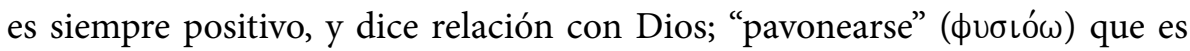

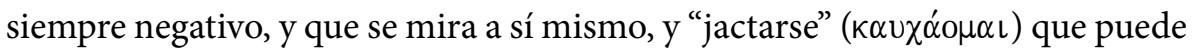
ser positivo o negativo según "en/de" qué es que uno se jacte. Jactarse de la propia capacidad, en el honor, se asemeja a "pavonearse", y es necedad; en cambio, "jactarse" en la obra de Dios, en la semejanza a la cruz, se asemeja a "gloriarse", deja transparentar la obra de Dios. Y este es el punto.

En la predicación sabia, poniendo en ella su confianza, algunos se "jactan" cuando deberían mirar la propia debilidad lo que les permitiría "jactarse en el Señor" $(1,31) .{ }^{24}$ Por otro lado, poniendo su confianza en la "sabiduría" de la predicación, no sólo eso les impide mirar la necedad de la cruz sino también la hacen vana al "confiar" en lo que no es la obra de Dios. La fe es confiar, edificar sobre roca, no sobre la buena predicación que termina tapando el escándalo. Una fe sabiamente afianzada (valga la redundancia) evita el riesgo de la idolatría siempre latente.

En la apología de Ga 1,13-24 Pablo debe defenderse de los ataques de los “judaizantes". Para ello remite a su pasado perseguidor. No es el caso destacar y clarificar algunos elementos que la unidad aporta para un mejor conocimiento de la vida de Pablo, lo interesante para nuestro tema es el contraste entre el "antes" y el "ahora" provocado por el momento revelador: Dios "tuvo a bien revelar en mi a su hijo para que lo evangelice entre los gentiles" y entonces Pablo comienza su nuevo recorrido comenzando por Arabia, Damasco, pasando brevemente por Jerusalén y yendo de allí a Cicilia y Siria. Ante este "nuevo Pablo", las "Iglesias de Judea que están en Cristo" no conocían el rostro de

\footnotetext{
${ }^{24} \mathrm{La}$ frecuencia de estos dos últimos términos es particularmente importante en las cartas a los corintios, lo que revela con qué tipo de comunidad nos encontramos: gloriarse (x62; Mt x4; Mc x1; Lc x9; Jn x23; Hch x5; Heb x1; 1 Pe x4; Ap x2; 2 Tes x1; y en Pablo: Ga x1; Rom x5; 1 Cor x2; 2 Cor $\mathrm{x} 3$ ); hincharse (x7, solo $\mathrm{x} 1$ en Col fuera de 1 Cor, $\mathrm{x} 6$ ); jactarse (x37; fuera de Pablo, sólo en Ef x1 y Sgo x2; Ga x2; Fil x1; Rom x5; 1 Cor x6; 2 Cor x20).
} 
Pablo $(1,22),{ }^{25}$ sólo habían oido decir: "el antes perseguidor, ahora evangeliza

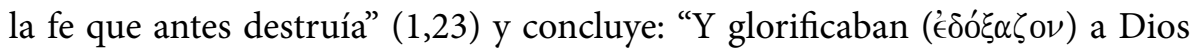
en mí" (24). Lo cierto es que se destaca que Pablo "ahora evangeliza la fe" ( $\nu$ v̂

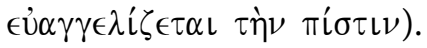

Si la fe es un don de Dios y de su espíritu, es un don mediado por la

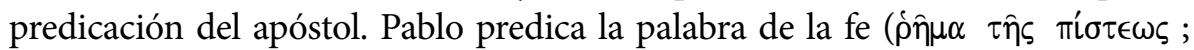
Rom 10,8), la que viene de la palabra de Cristo. Esta "palabra de la cruz", ante los ojos de los Gálatas lo "presentó gráficamente crucificado, a Jesús, el Cristo"

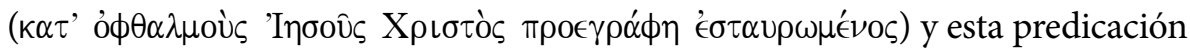
condujo a la fe y obtuvo el espíritu (Ga 3,1-2). Jesús mismo no permanece indiferente o distante de la predicación de Pablo: "otorga el espíritu y manifiesta

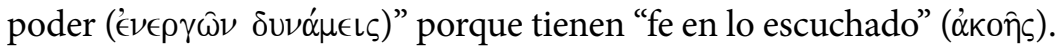

Esto lo repite en un texto sumamente claro. Algunos en Corinto niegan la resurrección (1 Cor 15,12), entonces Pablo -como lo hace en otros momentos de la carta, en situaciones críticas- remite a las fuentes. En este caso, a los eslabones de la cadena de la tradición de la que Pablo es sólo uno. Transmitírecibí $(15,1.3)$ remite a su propia escucha de otra predicación. En este caso, alude al cumplimiento de las escrituras de dos momentos principales: la muerte y la resurrección de Jesús (3b-4). Además de dicho cumplimiento, señala dos hechos visibles que permiten constatar los acontecimientos narrados: sepultura del muerto y las apariciones del resucitado. Puesto que el tema en cuestión en la unidad es la negación de la resurrección, es a estos testimonios que dedica más espacio señalando detalladamente los testigos que él conoce o que ha escuchado que han visto al Señor (5-8). ${ }^{26}$ En este caso, la lista comienza por el primero, Cefas, y finaliza por el último, Pablo mismo. Nuevamente alude a su pasado perseguidor, y señala que por mediación de la gracia ha "trabajado" ('€́отí $\alpha \sigma \alpha$ ), es decir "evangelizado" (1 Cor 4,12; Ga 4,11; Fil 2,16; cf. 1 Tes 5,12; 1 Cor 16,16; Rom 16,6.12) más que "todos ellos" (9-10). Y concluye toda esta sub-unidad con una frase fundamental: "sea yo, sean ellos, esto predicamos

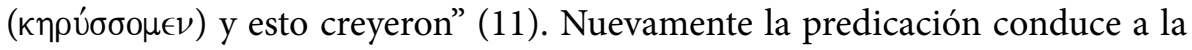

${ }^{25}$ Esta idea es la que hace sospechar a muchos estudiosos que Pablo no residía en Jerusalén (¿cómo no era conocido por los discípulos el temible perseguidor?) sino quizás en Damasco. De todos modos, el texto puede interpretarse en otro sentido, p.e. que no habían visto su rostro "ya cristiano", sino que la referencia a su "conversión" era solo "de oídas".

${ }^{26}$ Es llamativa la ausencia explícita de mujeres en la lista, siendo que algunos evangelios las mencionan. Es posible que estén disimuladas en los plurales masculinos (de hecho Junia [Rom 16,7] es llamada "apóstol", probablemente porque fue testiga del resucitado [cf. 1 Cor 9,1] y lo ha anunciado). Es posible que esta sea la lista que Pablo "ha recibido" y por eso transmite. 
fe, pero no refiere a una predicación retórica, o entusiasta, sino conducida por el espíritu, movida por la gracia, acompañada por Cristo mismo. La fe no es un mero "fruto" superficial de asentimiento amable; es un fruto firme de la obra de Dios en la comunidad con el apostol como mediador. Espíritu/gracia y fe son "causa y efecto".

\section{Fe e historia}

Sin embargo, es importante señalar que para Pablo la fe no es algo ni individual, ni etéreo. Es algo que se vive en una comunidad, es la comunidad la que es creyente, la fe es "nuestra fe".

- Fe comunitária

Hemos señalado que para Pablo los seguidores de Jesús son Israel. Podemos llamarlo "Israel del espíritu" (aunque el término no se encuentre; pero sí se encuentra "Israel según la carne", 1 Cor 10,18, e "Israel de Dios", $\mathrm{Ga}$ 6,16), y como tal su fe, es la fe de Israel, histórica y comunitaria. La descendencia de Abraham, para Pablo, refiere claramente a Cristo ya que el término está en singular (no dice "los descendientes"; Ga 3,16). La fe -en este contexto- es algo previsto para un momento histórico, "la Escritura encerró todo bajo el pecado, para que la promesa a la fe en Jesús Cristo fuera otorgada a los creyentes" $(3,22)$, por eso, “antes que llegara la fe" esperábamos la revelación de la fe custodiados por la ley (23). Esta fe llega (o llegamos a ella) con Cristo y "llegada la fe" ya no necesitamos la custodia o el pedagogo (25). La fe, por tanto, es algo que "llega" o hacia lo que la historia se dirige. Se refiere, evidentemente, al momento histórico de Cristo, "el descendiente" de Abraham, el "hijo de Dios". Al recibir el espíritu de Jesús, el hijo (2,20; 4,4), los seguidores de Jesús son también hijos de Dios $(4,6)$, la fe los hace "hijos de Dios" $(3,26)$, "el espíritu" (1 Cor 12,13). El bautismo sumerge "en Cristo" a los seguidores de Jesús, y "en Cristo" son hijos, son "revestidos", es decir unidos plenamente a Cristo (Rom 13,12.14; 1 Cor 15,53.54; 1 Tes 5,8). Este revestimiento sucede en el bautismo (Ga 3,27). Ahora, llegado el tiempo de la fe, se disuelven todas las diferencias que impedían a muchos y muchas acceder a Dios, y "en Cristo... ya no hay" acción de gracias "por haber nacido libre y no esclavo, judío y no pagano, varón y no mujer" ya que todos son "hijos de Dios", descendencia de Abraham, y por tanto hermanos y hermanas "en Cristo" y por tanto "uno" (28). 
El debate acerca de Pablo y el judaísmo ha tomado un nuevo "color" a partir de lo que se ha llamado la "nueva perspectiva" (E. P. Sanders, J. D. G. Dunn, N. T. Wright), ${ }^{27}$ y esto supone una nueva mirada del judaismo (más precisamente "judaísmos") de tiempos de Pablo, y por tanto, una nueva perspectiva para comprender los roles de la ley, la fe, la justificación, la relación con el imperio. Podríamos resumir la idea fundamental de que en cierto modo la "ley" caracteriza la identidad judía, pero al proponer la centralidad de la "fe" Pablo entra en esta "nueva perspectiva". La razón por la que para Pablo la ley no justifica es porque "Pablo redefine el pueblo a partir de la fe del Mesías... y porque la ley no justifica sino que revela el pecado". ${ }^{28}$ La revisión del judaismo desde los escritos de E. P. Sanders (judaísmo del Segundo Templo, el "coventantal nomism"), y los aportes de textos de Qumrán, particularmen 4QMMT, la insistencia en que el tema "las obras de la ley" alude a aquellos que se "jactan" particularmente de la circuncisión, aquellos que en la "elección" no destacan tanto la separación "para" Dios sino la separación "de" los demás pueblos. La nueva perspectiva ha ayudado no sólo a ver con otros ojos el judaísmo de tiempos de Pablo, sino también a mirar con otros ojos a Pablo frente al judaísmo. Evidentemente, la "justificación por la fe" debe entenderse en este marco y este contexto.

- Confesión de fe

La fe es fe cuando se confiesa; la gloria de Dios Padre llega cuando "toda rodilla se dobla" y "toda lengua confiese" que Jesús es Señor (Fil 2,11; Rom $14,11)$, los paganos "glorificarán" a Dios cuando se presente Cristo en medio de ellos y lo confesarán entre los paganos y ensalzarán su nombre (Rom 15,9). Esta confesión de la propia y común fe es un salir de uno hacia el acto salvador de Dios, participando de él. En 2 Cor 4,7 después de haber contrastado la vieja y la nueva alianza comienza a presentar la novedad que trae Jesús. Para eso una vez más Pablo se muestra en paralelo con Jesús señalando las marcas que le deja la predicación de la cruz: "llevamos en todas partes el morir de Jesús, a fin de que también la vida de Jesús se manifieste en nuestro cuerpo" (10); "pues,

\footnotetext{
${ }^{27}$ Una presentación de la "nueva perspectiva" en su génesis, críticas y malos entendidos, precisiones e historia, puede verse en DUNN, J. D. G., The New Perspective on Paul. Revised Edition, Grand Rapids, Michigan - Cambridge: W. B. Eerdmans Publ. Comp, 2008, particularmente "The New Perspective on Paul, whence, what and whither?", p. 1-97, especialmente p.1-17 y una breve síntesis de los 5 temas fundamentales en p. 16-17.

${ }^{28}$ WRIGHT, N. T., Justification. God's plan \& Paul's vision, Illinois: IVP Academic, 2009, p. 118.
} 
aunque vivimos, nos vemos continuamente entregados a la muerte por causa de Jesús, a fin de que también la vida de Jesús se manifieste en nuestra carne mortal". (11). Por eso en 4,13 comienza a destacar esa vida presente -"sabiendo que quien resucitó a Jesús también nos resucitará con Jesús" (14)- hablando del "hombre interior" (16), "morada eterna... celeste" $(5,1.2)$. Este grupo apostólico ("nosotros") posee el espíritu que es calificado "de fe", seguramente por ser el que habla en las escrituras que citará a continuación.

El texto "creí, por eso hablé" alude al Sal 116,10 (115,1 [LXX]). Es muy diferente el texto hebreo de su versión griega, y es esta la citada por Pablo:

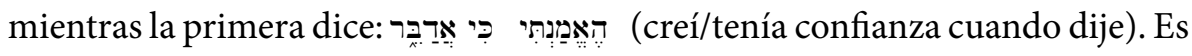
interesante en el Salmo el paralelo entre el v.10 y el v.1 en el que un personaje anónimo afirma que ama (v.1) / que cree (v.10), le sigue el clásico kî (כ) y un planteo de situación negativa (v.3 / v.11). LXX traduce "muy acertadamente"29 כ (kî) por su posible "por eso", y también lo introduce por un "aleluya": ${ }^{30}$

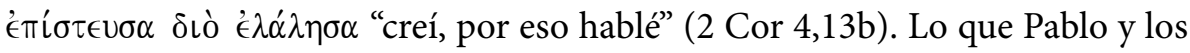
suyos hablan (pasa al plural, 13c) es algo que como judío Pablo sabe bien: con la resurrección de Jesús ha comenzado una nueva era, la de la resurrección de todos ( 1 Tes 4,14; 1 Cor 15,20), y entonces el sello de la cruz que caracteriza al apostolado, también está marcado por la fuerza de la vida. Cuantos más sean los que crean esto y acepten el mensaje del evangelio tanto más abundará la acción de gracias y darán "gloria" a Dios (15). Es este espíritu y esta fe la que da fuerza a Pablo para resistir la propia debilidad ("utensilio de barro", 4,7; "hombre exterior que se desmorona", 4,16) sabiendo que por sí solo él no es capaz de semejante ministerio, pero que "es capacitado" por Dios mismo para hacerlo (3,5-6). El "hablar", entonces, es el hablar evangelizador, el proclamar la fe y al resucitado, que no es para guardarla para sí sino para que sean "cuantos más posibles" los que den gracias a Dios y él sea glorificado.

\section{Contenido de la fe}

En realidad, podemos afirmar para comenzar que no hay otro contenido para la fe sino Dios mismo. Sólo en él se ha de poner la confianza, como lo hemos

\footnotetext{
${ }^{29}$ KRAUS, H. J., Los Salmos 60-150, Salamanca: Sígueme, 1995, e-book p. 538.

${ }^{30} \mathrm{La}$ "desdicha" del texto hebreo se transforma en "humildad"/ "humillación" en LXX; el aleluya parece entenderse por la diferencia; en el hebreo el orante "aunque" se reconoce desdichado, se manifiesta como creyente. Pone su confianza en Dios y no en el hombre, como corresponde a la verdadera fe [ALONSO S., L. -CARNITI, C., Salmos II (Salmos 73-150), Navarra: Verbo Divino 1993, e-book p. 467]; en LXX, en cambio, ante la humillación, por cuanto es creyente, habla.
} 
dicho, y es peligro contra la misma fe, o la fe recta, confiar en lo que no es dios, por más "divino" que esto sea. En realidad, entonces, más que "contenido" quizás debamos hablar de "características", pero en cierto modo también son contenidos siempre y cuando entendamos que lo son en la medida de Dios. Por ejemplo, para entender la idea que retomaremos en seguida: decir "creo en la resurrección" puede tener dos dimensiones, una correcta y la otra falsa. La resurrección no es una condición natural, no es parte de la naturaleza humana; en ese sentido podemos afirmar que creemos que no hay resurrección. Pero a su vez creemos que Dios resucitará a los muertos, y en ese sentido la naturaleza es apta para ser resucitada por Dios. Lo que creemos es que Dios resucitará a los muertos, no que estos resucitan "por sí solos". En este sentido hablamos de "contenidos".

Es interesante que como otros, con alguna frecuencia (Rom 4,9; 10,10; $16,26)$ Pablo en lugar de "creer en" prefiere "creer hacia" ( "acto de creer" define el ser de los cristianos ("creyentes"), y tiene una dimensión universal, ya que es para todos sin excepción. Es importante la importancia que da Pablo en Rom, una carta donde la fe ocupa tanto lugar, a la idea de "todos" (x70), como veremos, en un sentido universalista. Por otra parte, es de destacar que no se describe un crecimiento de la fe, sino simplemente que esta es necesaria para ser justificados. La fe es respuesta al Evangelio y a su vez suscita la proclamación, como decimos. El acto de creer es buena nueva proclamada y vivida. ${ }^{32}$

- Dimensión misionera

La estrecha relación entre fe y predicación remarca la importancia de la misión. Si la fe conduce a la justificación, la evangelización manifiesta una activa preocupación por la humanidad, por "todos" (Rom 1,16; 10,13; 1 Cor 10,33). Es llamativo que con mucha frecuencia Pablo escribe a sus destinatarios refiriendo a "la fe de ustedes" (Rom 1,8.12; 1 Cor 2,5; 15,14.17; 2 Cor 1,24; 10,15; Fil 2,17; 1 Tes 1,8; 3,2.5.6.7.10: cf. Fil 1,25; 1 Tes 1,3), lo colectivo evidentemente enfatiza la dimensión misionera de la fe.

${ }^{31}$ El diccionario BDAG señala -con muchas variantes en cada caso- dos acepciones de $\epsilon$ i $\zeta$ (entre aspas): 1. extensión de envuelve un lugar o una meta, dentro; en; y 2. extensión en el tiempo, hasta. El uso también se encuentra en Ex 19,9; Sir 40,12; Mt 18,6; Mc 9,42 (var. en A, B, pero no en $\wedge$ y $\Delta$, por ejemplo); frecuente en Jn: 1,$12 ; 3,16.18 .36 ; 6,29.35 .40 ; 7,38.39 ; 9,35.36$; 11,25.26.48; 12,36.44 (x2).46; 14,1.12; 16,9; 1 Jn 5,10.13; Hch 10,43; 20,21; Heb 10,39; Sgo 2,19; 1 Pe 1,5.21; y ausente en los escritos seudo-paulinos.

${ }^{32}$ ALETTI, J. N., "Lacte de croire pour l’Apôtre Paul", RSR 77/2 (1989) 233-250. 
- Resurrección

Como señalamos más arriba, la fe en la resurrección es fe en Dios que resucita. En la unidad que comentamos más arriba sobre la resurrección en

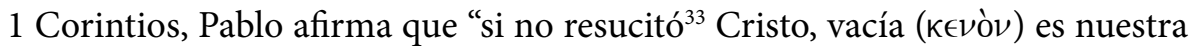

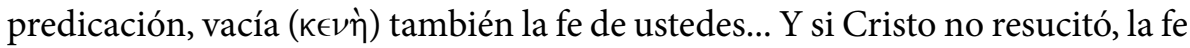
de ustedes es vana $(\mu \alpha \tau \alpha i \alpha)$ : están todavía en sus pecados" ( 1 Cor $15,14.17){ }^{34}$ Como dijimos, Dios es el autor de la resurrección de Jesús $(15,15)$ quien es "primicias de los que durmieron" (20). El texto está encadenado al que hemos comentado: la resurrección de Jesús dice relación al perdón de los pecados: "fue entregado por nuestros pecados, y fue resucitado para nuestra justificación" (Rom 4,25) y eso es "lo que predicamos", puesto que la predicación conduce a la fe; y suponiendo -como afirman algunos en Corinto- que no hay resurrección, la predicación es vacía y por tanto también lo es la fe. Pero la gracia de Dios en Pablo no ha sido "vacía" $(15,10)$ y por eso ha trabajado más que los demás, o mejor, la misma gracia ha trabajado; e invita a los lectores a seguir "trabajando" en el Señor, lo cual no es "vacío" (15,58), ya que se debe presentar al mundo la "palabra de vida" para "mi jactancia, ya que no habré corrido en vano ni trabajado en vano" (Fil 2,16), como no fue "vacía” la ida a Tesalónica (1 Tes $2,1 ; 3,5)$. La idea de vaciedad, como se ve, está ligada al trabajo apostólico que es todo lo opuesto, plenitud. La vanidad es característica de los pensamientos de los sabios ante el Señor (1 Cor 3,20). Por tanto, el trabajo / predicación del apóstol que conduce a la fe de los destinatarios de su palabra, sería vacío si no hubiera Dios resucitado a Jesús, y por tanto la fe de estos destinatarios lo sería. "Ahora bien, Cristo resucitó" $(15,20)^{35}$ y Pablo y todos los mencionados al comienzo de la unidad como beneficiarios de apariciones del resucitado, son testigos de ellos (caso contrario serían "falsos testigos" de Dios, 15,15).

Pero esta fe en la resurrección no es sólo creer que Dios resucitó a Jesús, y tampoco es dar el siguiente paso, esto es creer que Dios resucitará también a "los de Cristo" (23); todavía esto supone un paso más, un cambio sustancial de la persona. Entramos en la nueva era, la era del espíritu, y esto implica vivir coherentemente con eso. Cristo "murió por todos, para que ya no vivan para

\footnotetext{
33 "Resucitó" ('́үฑ์ $\gamma \in \rho \tau \alpha \iota)$ es pasivo perfecto, lo cual indica un "resucitador".

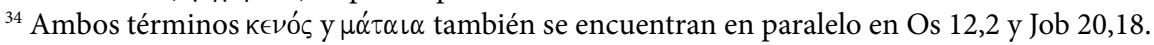

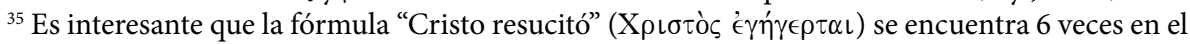
NT y todas ellas en 1 Cor 15 (vv. 12.13.14.16.17.20).
} 
sí los que viven, sino para aquel que murió y resucitó por ellos" (2 Cor 5,15), y esa vida comienza en el bautismo: "Fuimos, pues, con él sepultados por el bautismo en la muerte, a fin de que, al igual que Cristo fue resucitado de entre los muertos por medio de la gloria del Padre, así también nosotros vivamos una vida nueva" (Rom 6,4).

\section{- "Fe de Cristo"}

Un aspecto sumamente interesante e importante radica en el sentido con el que Pablo utiliza la "fe" cuando habla de Cristo... En algunas ocasiones habla de "la fe de Cristo/ Jesús / el hijo de Dios" (Rom 3,22.26; Ga 2,16.20; 3,22; Fil

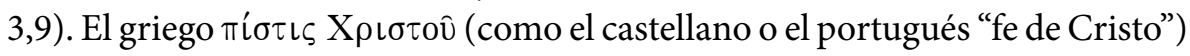
permite leerlo como un "genitivo subjetivo" o un "genitivo objetivo", es decir, entenderlo como fe "en Cristo" (Cristo objeto de la fe) o como la fe que tiene "Cristo" (Cristo sujeto de la fe/fidelidad). Hay pasajes -como vimos- en los que pisteuô va con "eis" (Rom 10,14; Ga 2,16; Fil 1,29) o con "epi" (Rom 9,33; $10,11)$ en los que no cabe duda que Cristo es el objeto de la fe, pero el tema del sentido de la $\pi i ́ \tau \iota \varsigma$ X $\rho\llcorner\sigma \tau o v$ es muy debatido y hay razones importantes $\mathrm{y}$ válidas en uno y otro lado. ${ }^{36}$ Hays, por ejemplo, señala que el paralelo entre la

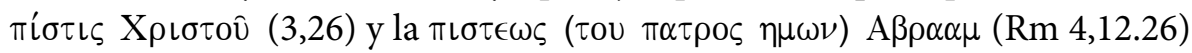
es una dificultad fatal para los que proponen un genitivo objetivo. Por otro lado, James D. G. Dunn recordando otras fórmulas como "celo de Dios" (Rom 10,2) destaca la posibilidad subjetiva. ${ }^{37}$ Ciertamente, la posibilidad de entender "pistis" no sólo como fe, sino también como fidelidad (= obediencia) ha reforzado la lectura subjetiva. ${ }^{38}$ En un detallado análisis, Matthew C. Easter

\footnotetext{
${ }^{36}$ Una buena referencia bibliográfica a ambas opiniones puede verse en HAYS, R. B., The Faith of Jesus Christ: The Narrative Substructure of Galatians 3,1-4-11, Gran Rapids, Michigan: W. B. Eerdmans, 2002 , p. 273, aludiendo a los que se inclinan por una lecura objetiva en nota 3 y por una lectura subjetiva en nota 4 , señalando al final de esta última nota (p. 274) una posición intermedia. Allí, por otro lado, respondiendo a Dunn señala que W. Schenk ve "muy claramente" que la interpretación (originada en la lectura apocalíptica de Käsemann) acerca de la "justicia de Dios" requiere una reinterpretación paulina de la comprensión de la pistis. También puede verse bibliografía en http:// epistletothegalatians.wordpress.com/faithfulness-inof-christ-bibliography/ con una indicación marginal si se trata de una opinión objetiva o subjetiva (consultado el 11/12/2012 16 hs).

${ }^{37}$ De todos modos, en 1 Cor 10,22 "los celos del Señor" (en acusativo) son celos evidentemente "de" y no "por" el Señor. El debate entre ambos se puede ver en HAY, D. M., - JOHNSON, E. E., Pauline Theology, vol 4: Looking Back, Pressing On, Atlanta: Scholars Press JBL 1997, con sendos artículos de cada uno (Hays p. 35-60; Dunn, p. 61-81) y una respuesta de P. J. Achtemeier (p. 88-92).

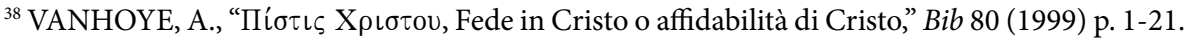


muestra la viabilidad de ambas posiciones y concluye afirmando que:

"el presente estado del debate sugiere que ambas traducciones son viables. Sin embargo, los intérpretes deben tomar una decisión por una de las dos o intencionadamente abogar por alguna combinación de ambas. Matlock acierta al afirmar que ambas lecturas, o una combinación de ellas no prevalecen simplemente en virtud de nuestra dificultad para escoger ' (2009: 88). Entonces el debate continúa. Al avanzar, los intérpretes se encuentran en aprietos con las suposiciones hermenéuticas y teológicas mucho más grandes que están en el juego en ambos lados". ${ }^{39}$

En este trabajo -puesto que se acaba de decir que "debemos tomar una" opinión- nos resultan convincentes los argumentos de Jouette M. Bassler en favor de una lectura subjetiva: a nivel gramatical, en el judaísmo helenista la construcción siempre se entiende de modo subjetivo; en las cartas de Pablo, las

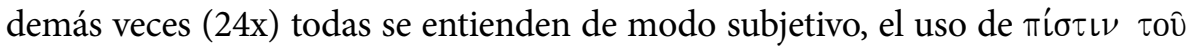
$\theta \in$ єô (Rom 3,3) es claramente subjetivo, los romanos -que no conocen a Pablo ni sus giros, si debiera entenderse de modo objetivo- lo habrían entendido de modo subjetivo; y siguiendo a Morna Hooker, luego de preguntarse, como diremos, cómo se produce la justificación, si por imitación, identificación, o una unión mísitica, afirma que se trata de una fusión, estando "en Cristo" los seguidores de Jesús adquieren su fe. Fe y bautismo, entonces, se implican mutuamente (como el huevo y la gallina, acota irónicamente). "La fe puede manifestarse por la obediencia a la ley (Rom 8:4), pero no está restringido a esto y está también abierto a todos. Y en una lectura de Rom 3:21-2 2, la fidelidad de Cristo revela y realiza la propia fidelidad de Dios a la alianza con Israel”.40

Esta posición, por otro lado, tiene la ventaja de "reconciliar a Pablo con los Evangelios" ya que refiere a la "fidelidad" (= obediencia) del Jesús histórico, refuerza el valor que para Pablo tiene la humanidad de Jesús, que había quedado desvalorada al menos desde R. Bultmann, ${ }^{41}$ y reconcilia la lectura

${ }^{39}$ EASTER, M. C., "The Pistis Christou Debate: Main Arguments and Responses in Summary", CBR 9 (2010), 33-47, 44. La cita de Matlock se refiere a 'Saving Faith: The Rhetoric and Semantics

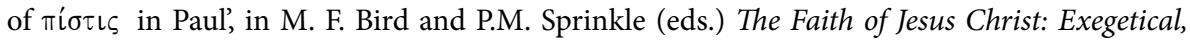
Biblical, and Theological Studies, Milton Keynes: Paternoster 2009, p.73-89.

${ }^{40}$ BASSLER, J. M., Navigating Paul. An Introduction to Key Theological Concepts, Westminster:

J. Knox Press 2007, p. 27-33, 33.

${ }^{41}$ Es sabido que para Rudolf Bultmann, el "Jesús histórico" no es importante en los escritos de 
aparentemente jurídica de la "justificación” con el acontecimiento escatológico del bautismo, puesto que la fe supone "participación en Cristo".

\section{Fe como adhesión a una persona}

La característica esencial de los destinatarios de las cartas de Pablo es su fe, los llama "creyentes", y a veces también santos, amados, elegidos, llamados... Se caracterizan (o debieran) por el amor, la esperanza, la justicia, la paz, la resistencia; pero cuando Pablo señala qué dice de ellos, destaca su fe (1 Tes 1,8; 3,5.7-9).

La fe define la relación con Dios (4 Mac, Sir, Filón), y la autodefinición del judaísmo en relación a Dios. Sin embargo, muchos en el judaísmo (y en el judaísmo seguidor de Jesús) creen que la relación con Dios se concreta en la obediencia a la ley, mientras Pablo la relaciona con Cristo, y no sólo en cuanto verdad (como lo hace el judaísmo; entendiendo "verdad" en sentido semítico, no griego, obviamente), sino especialmente con el evangelio. A veces, como es habitual, el acento se pone en el contenido (aquello en lo que se cree, como "que Dios lo resucitó", Rom 10,9; 1 Tes 4,14), otras veces tiene connotaciones existenciales, o morales ("obediencia de la fe", Rom 1,5; 16,26; cf. 10,16), incluso mostrando el ejemplo de Abraham (4,16-22). Creer en Dios / Cristo supone creer que lo que se dice de Dios / Cristo es cierto aun antes de proclamarlo, y a esto antecede como se vive. La fe es la respuesta apropiada (y salvífica) ante el evangelio (Rom 10,5-17; 1 Cor 15,1-2; 1 Tes 1,2-8).

En algunas cartas (especialmente Gálatas y Romanos) Pablo contrasta la fe con otro modo de relación con Dios: la ley. Para Filón, la fe es "la más perfecta de las virtudes" (Her 91), ${ }^{42}$ directamente relacionada con Abraham en función de la verdad: Abraham creyó en las promesas de Dios “y siguió la ley y los mandamientos divinos" (Abr 275). ${ }^{43}$ Fe y obediencia van juntos, en Filón, no son opuestos. Los Macabeos ante las torturas, se ven fortalecidos por su fe

Pablo; cf. BULTMANN, R., "La signification de Jésus historique pour la théologie de Paul”, en R. Bultmann, Foi et compréhension, Paris: Seuil, 1970.Tomo 1, p. 211-239, lo cual acentúa la importancia del "kêrygma"; recientemente, el tema se ha relativizado; U. Schnelle, por ejemplo, al referir al misterio pascual de 1 Cor 15 habla de "concentración narrativa", en SCHNELLE, U., Apostle Paul. His Life and Theology, Michigan: Baker Academic, 2005. 106; cf. BARBAGLIO, G., Pablo y Jesús, Salamanca: Secretariado Trinitario 2009; THISELTON, A., The Living Paul. An Introduction to the Apostle's Life and Thought, Illinois: IVP, 2010, p. 1-10.

${ }^{42}$ FILÓN DE ALEJANDRÍA, Quis rerum divinarum heres sit 91, Obras Completas t.III, p.14.

${ }^{43}$ FILÓN DE ALEJANDRÍA, de Abraham 275, Obras Completas t.III p.254. 
y creen que -como Abraham, Isaac y Jacob- vivirán para Dios (4 Mac 7,16-23; $16,22)$, su fe se muestra en la fidelidad a la ley $(13,13)$. Sirácida identifica en un paralelismo poético, fe y obediencia a la ley: "El que confía ( $\pi\llcorner\sigma \tau \epsilon u ́ \omega \nu)$ en la ley

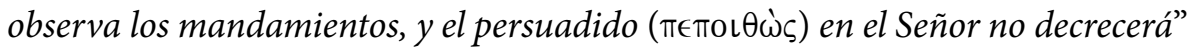
$(32,24)$. Fe y obediencia son dos caras de la misma moneda. Pablo, en cambio, con frecuencia los presenta como antitéticos $(\mathrm{Ga} 2,16) .{ }^{44} \mathrm{La}$ fe parece oponerse no a la jactancia humana y los méritos, sino a la autoconfianza judía basada en ser pueblo de la ley.

"El corazón de la teología de Pablo sobre la justificación era la interacción dinámica entre 'la justicia de Dios' como acción salvadora de Dios para todos los que creen, y 'la justicia de Dios' y la fidelidad de Dios a Israel su pueblo elegido". ${ }^{45}$

La fe es en Dios, es a él a quien se obedece (Rom 6,13.22), a quien se le cree (Rom 4,5) y en cuyas promesas se confía (Rom 10,9), de allí que se hable de "obediencia de la fe" (Rom 1,5; 16,26). Pero esa fe se dirige a la obra de Dios en la muerte y resurrección de Cristo, la salvación que Dios ofrece por ellas. Podemos preguntarnos, por ejemplo, como lo hemos señalado ¿Cómo salva la fe de Jesús? ¿Por imitación, por identificación, por una unión mística con él? A modo sintético señalemos que esta unión se relaciona con el bautismo (eis implica movimiento), es fusión. ${ }^{46}$

La idea paulina de que "en Cristo Jesús ni la circuncisión ni la

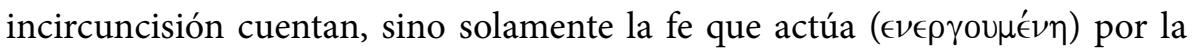
caridad" (Ga 5,6) manifiesta que la fe se hace visible en el amor. Es interesante que Pablo -jel fariseo!- casi no habla de "amar a Dios" (= decálogo), y no habla de amar a Cristo; todo eso está englobado en la idea de la fe. Sólo la fe cuenta.

\section{Breve nota}

Siendo, como lo hemos afirmado, que Pablo escribe una "teología en epístola", parece oportuno, aunque brevemente, notar algunos acentos, diferencias o elementos propios de cada carta en lo que respecta a la fe:

\footnotetext{
${ }^{44}$ Quizás poniendo cuidado al riesgo de transformar consciente o veladamente la fe como una -o la más importante- de las obras.

${ }^{45}$ DUNN, J.D.G., The Theology of Paul the Apostle, Grand Rapids Michigan: W. B. Eerdmans Co., ${ }^{2} 2006$, p. 344.

${ }^{46}$ BASSLER, J. M., Navigating Paul, 31.
} 
- Fe en 1 Tes [sustantivo 8x; verbo 5x]. En ningún momento se destaca el objeto de la fe: se la supone, y a los destinatarios los llama "creyentes" (1,7; $2,10.13)$, con frecuencia alude a la "fe de ustedes" $(1,8 ; 3,2.5 .6 .7 .10)$, aunque señala que temió por la suerte de la fe $(3,2)$ y se preocupó por "afianzarla" $(3,3)$ y "enmendarla / prepararla" $(3,10)$, y se alegra por la buena noticia de que conservan la fe $(3,6.7)$. Dos veces, al comienzo y al final pone la fe en un cierto mismo nivel que la esperanza y el amor $(1,3 ; 5,8)$. Pablo recuerda su paso por Tesalónica afirmando que fue "evaluado" por Dios que le confió el evangelio

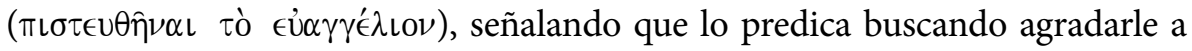
Dios mismo $(2,4)$. Finalmente, en el contexto de la muerte de algunos miembros de la comnuidad $(4,14)$ manifiesta su fe en la muerte y resurrección de Jesús como primer paso que Dios da en la futura resurrección de los que "durmieron por Jesús". Siendo que la carta a los Tesalonicenses no destaca de un modo importante la obra salvadora de Cristo, mientras celebra que los tesalonicenses "abandonaron los idolos para servir al Dios vivo y verdadero" $(1,9)$ podemos señalar que en ella la fe que Pablo presenta es más teo-lógica que cristo-lógica; supone un afirmarse en Dios y su obra y confiar en ella.

- Fe en 1 Cor [sustantivo 7x; verbo 9x] Además de usar el término una vez en sentido popular ("creo que es asi": 11,18), y dos veces en un sentido que parece especial, como aludiendo a un tipo especial de fe $(12,9 ; 13,2)$ Pablo empieza a reforzar el rol de los ministros de la predicación (Pablo y Apolo, 3,5) ya que la predicación es para la fe $(2,4)$, y evangelizar es una misión que se le ha confiado

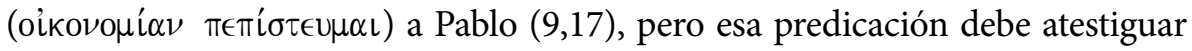
la obra de Dios para que no sea una fe hueca $(15,2)$, vacía $(15,14)$, vana $(15,17)$ y Pablo pretende que estén "firmes en la fe" $(16,13) .{ }^{47}$ Los corintios son tenidos por "creyentes" $(1,21 ; 14,22)$ ya que han escuchado y recibido la predicación $(15,11)$. La fe tiene una relación cercana con la esperanza y con el amor $(13,7.13)$. Podemos destacar que en esta carta la fe es presentada especialmente como un don de Dios y su espíritu para la comunidad.

- Fe en Fil [sustantivo 5x; verbo $1 \mathrm{x}$ ] En un contexto conflictivo con el Imperio, Pablo destaca la importancia de una nueva "ciudadanía" según el Evangelio; en esta, creer es una gracia, como lo es asemejarse al Cristo que aceptó

\footnotetext{
${ }^{47}$ Es interesante notar que para Pablo, el contraste entre una fe "vacía" (1 Cor 15,17), vana" (1

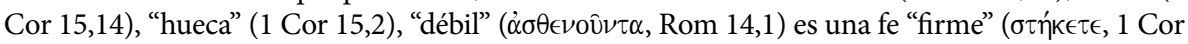

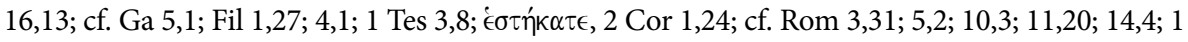

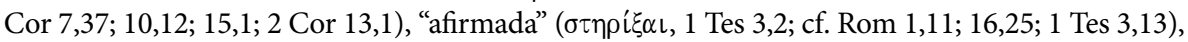

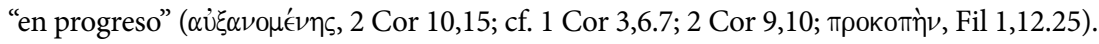


la muerte "y muerte de cruz" (2,8), es luchar por la "fe del Evangelio" (1,27-30) y el ministerio de Pablo se presenta, así, beneficioso para la fe de la comunidad $(1,25)$. La fe es una ofrenda -la vida lo es- que puede llegar a mezclarse con la sangre ofrecida por Pablo si es ejecutado $(2,17)$. En un cambio de tono, que puede deberse a una nueva redacción de la carta, o a una carta diferente, el conflicto se dirige a aquellos que insisten en la circuncisión como necesaria para la salvación; a ellos les recuerda (preparando lo que dirá en Gálatas y Romanos) que la justicia viene de Dios, viene de la fe, no de la ley. Pablo se pone de 'exemplum' y señala que no pone su confianza "en la carne", sino "en Cristo".

- Fe en Flm [sustantivo 2x] En la acción de gracias de la carta, Pablo

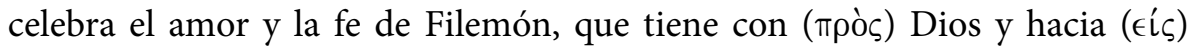
"todos los santos"; virtudes que son bien conocidas (5). Y pretende que esa

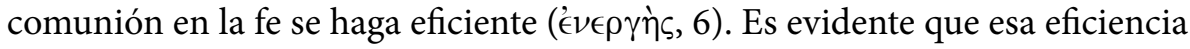
se da en relación a los santos (5.7) y que pretende que sea efectiva en el trato de Filemón a Onésimo como hermano (16). Pablo confia en la "obediencia" (ंт๘кой) de Filemón como consecuencia de su fe.

- Fe en 2 Cor [sustantivo 7x; verbo 2x] La situación de la carta es tensa y conflictiva, Pablo debe defenderse en más de una ocasión; debe recordarles que no pretende dominar la fe de los corintios $(1,24)$ sino que se goza de su firmeza, y su progreso $(10,15)$ y contribuye a ello. Precisamente porque no es "dueño", los invita a evaluarse ellos mismos, a probar su fe y reconocer a Jesús en ustedes $(13,5)$. Nuevamente -como en 1 Corintios- la fe a veces parece un carisma particular $(8,7)$, e incluso una vez -en contexto conflictivo, nuevamente- señala que "caminamos en la fe, no en la visión" (5,7). Pero Pablo, (y los suyos) ministro del Evangelio, habla movido por la fe, para que sean el mayor número posible los que reciban la gracia $(4,13)$.

- Fe en Gál ${ }^{48}$ [sustantivo 22x; verbo 4x] La importancia de la fe en Gálatas nos invita a una mirada más estructural, para comenzar. En un comienzo polémico por la predicación de misioneros judaizantes de "otro Evangelio" (1,69), Pablo recuerda que antes quería destruir la fe que ahora predica $(1,13.23)$. Su predicación, concretamente (porque se le confió [ $\pi \in \pi i \sigma \tau \epsilon \cup \mu \alpha \iota$; pasivo divino] el evangelio a los gentiles, 2,7) se presenta en forma de quiasmo:

\footnotetext{
${ }^{48}$ VANHOYE, A., "La fede nella letera ai galati”. En J. A. Noratto G. (Comp.) A la luz y al servicio de la Palabra (Hom. al P. Pedro Ortiz Valdivieso), Bogotá: Universidad Javeriana 2006, p. 247-268.
} 
A."sabiendo que no se justifica el hombre

B. por las obras de la ley

C. sino por $(\delta\llcorner\grave{\alpha})$ la fe de Jesucristo,

D. también nosotros en $(\epsilon i \varsigma)$ Cristo Jesús creimos

C. para la justificación por ('€́) la fe de Cristo,

B. y no por las obras de la ley, pues por las obras de la ley

A. no será justificada toda carne" $(2,16)$.

En el centro del quiasmo Pablo les recuerda a sus lectores que él (y los suyos) han creído. En la unidad teológica, o doctrinaria (3-4), Pablo desarrolla teológicamente el tema. Empieza señalando que los Gálatas recibieron el espíritu por la predicación que condujo a la fe $(3,2.5)$. Luego recurre (y lo hará más de una vez en la carta) al ejemplo de Abraham; sin duda porque los adversarios cuestionan a Pablo no ser (buen) judío, y él remite a las fuentes. Puesto que Abraham creyó, los que viven de la fe son hijos de Abraham (3,6-7). Nuevamente recurre a Abraham en quien son bendecidas todas las naciones (= los paganos) y esto no ocurre por la ley sino por la fe ya que "el justo vivirá por la fe" ${ }^{49} \mathrm{y}$ por la fe recibimos el espíritu de la promesa (3,8-14). En 3,15-29 nuevamente insiste en que Cristo es descendencia de Abraham, y por lo tanto lo son "los de Cristo", los que están sumergidos "en Cristo" por el bautismo y son por tanto, herederos de la promesa. ${ }^{50}$ En la unidad parenética (5-6) recuerda que la fe actúa por el amor y que es un fruto del Espíritu $(5,6.22)$ y que la fe mueve a aguardar la justicia que esperamos" $(5,5)$. Como en otras cartas, Pablo se refiere a los destinatarios como creyentes (3,22; cf. 6,10).

Es interesante que Galatas y Romanos concitan la casi totalidad de veces

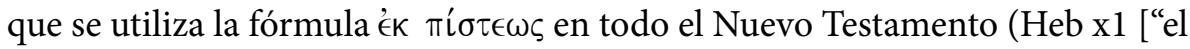
justo vivirá por la fe", 10,38], Sgo x1 y Ga x9; Rom x12). ${ }^{51}$ En general la fe se contrapone a las obras de la ley, aunque es importante recordar, como se ha dicho, que no debe entenderse en el sentido de que "todos los judíos", o que "ningún judío" reconocía la fe o la gracia sino la "sola ley”. El texto de Qumrán 4QMMT es tenido en cuenta -con razón- por Dunn y Wright para mostrar que en el judaismo ("los judaismos") había diferentes opiniones. ${ }^{52}$

${ }^{49} \mathrm{El}$ texto hebreo de Habacuc dice otra cosa, pero el texto griego permite esta lectura ya que

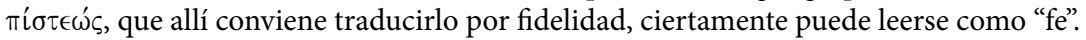

${ }^{50}$ La promesa es tema importante en la unidad (3,14.16.17.18.21.22.29) y en 4,23.28.

${ }^{51}$ Según BDAG el término tiene diferentes acepciones: separación, dirección, origen o causa, en perífrasis, "de", secuencia temporal, "desde"... esto marca la ambigüedad del uso paulino y permite entenderlo desde "por la fe" hasta sencillamente como "creyentes".

${ }_{52}$ DUNN, J.D.G., "4QMMT and Galatians". En J.D.G. Dunn, The New Perspective on Paul, 
- Fe en Rom [sustantivo 40x; verbo 21x] Señalamos que la carta comienza y termina con una referencia a la "obediencia de la fe" $(1,5 ; 16,26)$. Ciertamente esta inclusión no es azarosa. Hay muchos elementos en común con Gálatas en referencia a las obras de la ley, la justificación, Abraham. Veamos algunos aspectos importantes. En la introducción Pablo empieza destacando la centralidad de la fe en su Evangelio: este es "fuerza de salvación de Dios para todo el que cree" $(1,16)$, en el evangelio se revela la justicia de Dios "de fe en fe"

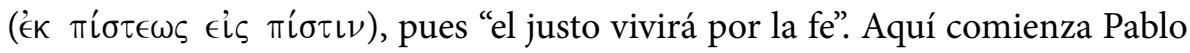
una larga cantidad de veces en las que resalta que el evangelio es para "todos", como se ha dicho. Sin embargo, después de esta presentación en la carta, el tema desaparece hasta $3,2 . .^{53}$

Es que Pablo se dedicó a señalar la fuerza del pecado en paganos y judíos. $\mathrm{El}$ acento que quiere destacar en esta parte es que "todos" pecaron. Señalado este pecado universal, destaca que la justicia de Dios se manifiesta "por la fe", para "todos los que creen", "circuncisos" e "incircuncisos" son justificados por la fe $(3,30)$. A partir del c.4 repite el ejemplo de Abraham, presentado como "padre de todos los creyentes incircuncisos" $(4,11)$ y "padre también de los circuncisos" $(4,12)$. Es interesante que terminada esta presentación teológica de "la justificación por la fe" y su ejemplo en Abraham, el tema vuelve a desaparecer hasta 9,30 (sólo encontramos el término en 6,8). En realidad, en 5,12-8,39 Pablo saca las consecuencias que tiene la nueva vida de la gracia, que nos ha liberado del pecado, de la muerte y de la ley. Pero en 9-11 Pablo intenta mostrar el lugar actual (y pasado) de Israel, y responder a la pregunta que él mismo se formula de por qué sus hermanos, "congéneres según la carne" $(9,3)$, no han aceptado a Cristo. En el cap. 10 partiendo de textos bíblicos volverá a la idea ya insinuada de que todos los creyentes se salvarán (paganos, 11,25 y judíos, 11,26); ya no hay distinción entre judíos y paganos, "uno mismo es el Señor de todos" (10,12), y "todo el que invoque el nombre del Señor se salvará" (13). En este contexto, Pablo remite a su propio ministerio donde resalta que

p. 339-345; WRIGHT, N.T., “4QMMT and Paul: Justification, 'Works', and Eschatology”. En Aang-Won (Aaron) Son (ed.), History and Exegesis: New Testament Essays in Honor of Dr E. Earle Ellis for His 80th Birthday, New York and London: T \& T Clark, 2006, p. 104-132; cf. también BACHMANN, M., "Identität bei Paulus: Beobachtungen am Galtaresbrief”, NTS 58 (2012) p. 571-597 sobre "el Israel de Dios" y referencias a 4QMMT].

${ }^{53}$ De todos modos en 3,2 y 3 el uso no sigue la línea del sentido teológico de la carta: "confiados los oráculos" y "fidelidad de Dios". Se debe esperar a v.22 para comenzar a hablar de la justificación y la fe en Cristo. 
para que invoquen el nombre del Señor, deben creer, para creer, deben oír, para oír se debe haber predicado, y para predicar se debe haber sido enviado (10,14-15). Esta cadena, típicamente paulina remite al tema ya mencionado de que la predicación engendra la fe. Es importante retener que con toda claridad afirma que "si confiesas con tu boca que Jesús es Señor y crees en tu corazón que Dios le resucitó de entre los muertos, serás salvado. Pues con el corazón se cree para conseguir la justicia, y con la boca se confiesa para conseguir la salvación". El paralelo entre corazón y boca se manifiesta en el otro paralelo creer-confesar que nos recuerda el dicho "creí, por eso hablé" (2 Cor 4,13). En la unidad parenética, Pablo invita a ser cuidadosos de los "débiles en la fe"

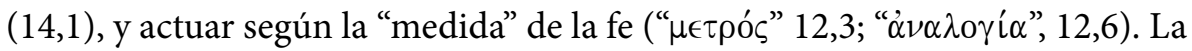
estrecha relación entre fe y predicación queda más evidente en esta carta; y el acento está puesto en que se predica "a todos" para que "todos crean", y "todos se salven".

\section{Conclusión}

A modo de conclusión, queremos repetir lo que ya hemos escrito y que parece sintetizar lo aquí expresado:

"La Fe: La fe no es algo de la "cabeza", sino algo del corazón. La fe no es algo que se entiende, sino algo hacia lo que se tiende; la fe es una vida que se edifica, es estar firmes sobre una roca. Por eso la fe se expresa en el amor: unidos a Cristo, lo único que importa es la fe que actúa por el amor $($ Ga 5,6) ya que una fe sin amor no es nada (1 Cor 13,2). Para Pablo es hombre de fe uno que ha edificado su vida sobre Cristo". ${ }^{4}$

\section{Referências Bibliográficas}

ALETTI, J. N., "L'acte de croire pour l'Apôtre Paul”, RSR 77/2 (1989) 233-250. ALONSO S., L. - CARNITI, C., Salmos II (Salmos 73-150), Navarra: Verbo Divino 1993, e-book

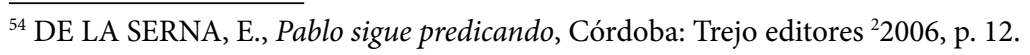


ÁLVAREZ, D., Pablo y el Imperio Romano, Salamanca: Sígueme 2009

BACHMANN, M., "Identität bei Paulus: Beobachtungen am Galtaresbrief", NTS 58 (2012) p. 571-597

BARBAGliO, G., La Teología de San Pablo, Salamanca: Secretariado Trinitario 2005

BARBAGLIO, G., Pablo y Jesús, Salamanca: Secretariado Trinitario 2009

BASSLER, J. M., Navigating Paul. An Introduction to Key Theological Concepts, Westminster: J. Knox Press 2007

BULTMANN, R., "La signification de Jésus historique pour la théologie de Paul", en R. Bultmann, Foi et compréhension, Paris: Seuil, 1970.Tomo 1, p. 211-239

CLARK, Anna J., Divine Qualities. Cult and Community in Republican Rome, Oxford: Oxford University Press, 2007

DE BOER, M. C., Galatians. A Commentary, Louisville-Kentucky: Westminster J. Knox Press, 2011

DE LA SERNA, E., "El kerigma de Pablo. Una mirada al ministerio paulino", Theologica Xaveriana 61 ( $\mathrm{N}^{\mathrm{0}}$ 172) (2011/2) p. 509-536.

DE LA SERNA, E., "La figura de Pedro en los escritos de Pablo", RevistB 70/3-4 (2008) p. 133-171

DE LA SERNA, E., "La Idolatría en 1 Corintios, ¿Una Clave de Interpretación?" En V. M. Fernández y C. M. Galli (eds.), "Testigos... y Servidores de la Palabra" Lc 1,2. Homenaje a Luis Heriberto Rivas, Buenos Aires: San Benito, 2008, 111-134.

DE LA SERNA, E., Pablo sigue predicando, Córdoba: Trejo editores ${ }^{2} 2006$

DUNN, J. D. G., The New Perspective on Paul. Revised Edition, Grand Rapids, Michigan - Cambridge: W. B. Eerdmans Publ. Comp, 2008

DUNN, J.D.G., "4QMMT and Galatians". En J.D.G. Dunn, The New Perspective on Paul, p. 339-345

DUNN, J.D.G., The Theology of Paul the Apostle, Grand Rapids Michigan:

W. B. Eerdmans Co., ${ }^{2} 2006$

EASTER, M. C., "The Pistis Christou Debate: Main Arguments and Responses 
in Summary", CBR 9 (2010), 33-47

ELLIOT, J., Un hogar para los que no tienen patria ni hogar: estudio critico social de la Carta primera de Pedro y de su situación y estrategia, Navarra: Verbo Divino, 1995

FILÓN DE ALEJANDRÍA, Obras Completas, Buenos Aires: Acervo Cultural 1975 (5 volúmenes)

GARNSEY, Peter and SALLER, Richard, "Patronal Power Relations". En: R. Horsley, (ed.), Paul and Empire. Religion and Power in Roman Imperial Society, Pennsylvania; Trinity Press International 1997

HAY, D. M., - JOHNSON, E. E., Pauline Theology, vol 4: Looking Back, Pressing On, Atlanta: Scholars Press JBL 1997

HAYS, R. B., The Faith of Jesus Christ: The Narrative Substructure of Galatians 3,1-4-11, Gran Rapids, Michigan: W. B. Eerdmans, 2002

KRAUS, H. J., Los Salmos 60-150, Salamanca: Sígueme, 1995, e-book

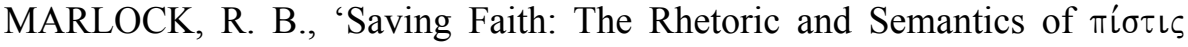
in Paul', in M. F. Bird and P.M. Sprinkle (eds.) The Faith of Jesus Christ: Exegetical, Biblical, and Theological Studies, Milton Keynes: Paternoster 2009, p.73-89.

MARTIN, D. B., New Testament History and Literature, New Haven-London: Yale University Press 2012

R. Horsley, (ed.), Paul and Empire. Religion and Power in Roman Imperial Society, Pennsylvania: Trinity Press International 199

SCHNELLE, U., Apostle Paul. His Life and Theology, Michigan: Baker Academic, 2005

SICRE, J. L., Introducción al profetismo bíblico, Navarra: Verbo Divino 2011

SIM, D.C., "Matthew's Antipaulinism: A neglected feature of Matthean Studies", HTS 58/2 (2002) p. 767-783.

THISELTON, A., The Living Paul. An Introduction to the Apostle's Life and Thought, Illinois: IVP, 2010

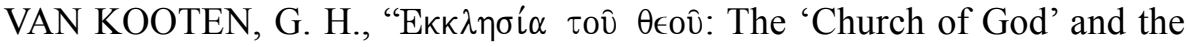
Civic Assemblies ('́кK $\left.\lambda \eta \sigma^{\prime} \alpha \iota\right)$ of the Greek Cities in the Roman Empire: 
A Response to Paul Trebilco and Richard A. Horsley", NTS 58 (2012) p. $522-548$

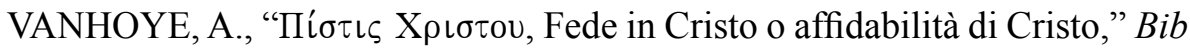
80 (1999) p. 1-21

VANHOYE, A., "La fede nella letera ai galati”. En J. A. Noratto G. (Comp.) A la luz y al servicio de la Palabra (Hom. al P. Pedro Ortiz Valdivieso), Bogotá: Universidad Javeriana 2006, p. 247-268.

WRIGHT, N. T., Justification. God's plan \& Paul's vision, Illinois: IVP Academic, 2009.

WRIGHT, N.T., “4QMMT and Paul: Justification, 'Works', and Eschatology”. En Aang-Won (Aaron) Son (ed.), History and Exegesis: New Testament Essays in Honor of Dr E. Earle Ellis for His 80th Birthday, New York and London: T \& T Clark, 2006, p. 104-132.

Eduardo de la Serna

Docente no Instituto Salesiano de Estudios Teológicos de Buenos Aires Professor Convidado na Pontificia Universidad Javeriana de Bogotá - Colombia Professor de Novo Testamento E-mail: edelaserna96@gmail.com

Recebido em: 25/09/12 Aprovado em: 14/03/13 